\title{
O VULCANISMO BIMODAL DO TIPO UATUMÃ DA REGIÃO DE SÃO FÉLIX DO XINGU (PA), PROVÍNCIA MINERAL DE CARAJÁS
}

\author{
CARLOS MARCELLO DIAS FERNANDES ${ }^{1,2}$, CLAUDIO NERY LAMARÃ ${ }^{1,3} \&$ \\ NILSON PINTO TEIXEIRA (IN MEMORIAM)
}

\begin{abstract}
Resumo Estudos petrográficos e análises químicas em rocha total confirmaram a existência de um vulcanismo bimodal, ocorrente nas proximidades do município de São Félix do Xingu, centro-sul do Estado do Pará, que resultou em depósitos de lavas traquibasálticas, andesito-basálticas, traquiandesíticas, andesíticas, dacíticas, traquíticas e riolíticas, e de fluxo piroclástico representado por tufos vítreos e de cristais e brechas polimíticas, pertencentes às Formações Sobreiro e Iriri, do Grupo Uatumã. As rochas pertencentes à Formação Sobreiro são metaluminosas, de natureza cálcico-alcalina transicional entre as séries de rochas de alto-K a shoshonítica e de afinidade geoquímica de arco vulcânico transicional entre imaturo e maturo, formadas pelo fracionamento de clinopiroxênio, anfibólio e plagioclásio. As rochas da Formação Iriri são metaluminosas a peraluminosas, transicionais entre as séries subalcalina e alcalina, de afinidade geoquímica intraplaca, regida predominantemente pelo fracionamento de feldspatos. A associação vulcânica da região de São Félix do Xingu foi formada, provavelmente, entre final de um evento orogênico e o início de uma fase de rift intracontinental, o que pode estar relacionado à tafrogênese de 1,88 Ga registrada em praticamente todo o Cráton Amazônico
\end{abstract}

Palavras-chave: petrografia, geoquímica, bimodal, Uatumã, Cráton Amazônico

\begin{abstract}
THE BIMODAL UATUMÃ TYPE VOLCANISM FROM THE SÃO FÉLIX DO XINGU (PA) REGION, CARAJÁS MINERAL PROVINCE. Petrographical and geochemical whole rock data allowed recognition of a bimodal volcanism, which occurs in the São Félix do Xingu region, southeast of the Pará state, resulting trachybasaltic, basaltic-andesite, trachyandesitic, andesitic, dacitic and trachytic lavas deposits, as well pyroclastic flow represented by glassy and crystal tuffs and polimitic breccias, grouped in the Sobreiro and Iriri formations of the Uatumã Group. The Sobreiro Formation rocks are metaluminous in composition, fall in the field of calc-alkaline transitional from high-K to shoshonitic series and shows geochemical signature of rocks of mature to immature volcanic arc, formed by clinopyroxene, amphibole and plagioclase fractionation. The Iriri Formation rocks are of metaluminous to peraluminous composition, transitional between subalkaline to alkaline series of rocks and present geochemical composition of intraplate magmatism, predominantly formed by feldspars fractionation. The volcanic association from the São Félix do Xingu (PA) region was formed between in a latest stage of subduction event and earliest stage of continental rift, related to the taphrogenetic event of $1.88 \mathrm{Ga}$ registered in most Amazonian Craton.
\end{abstract}

Keywords: petrography, geochemistry, bimodal, Uatumã, Amazonian Craton

INTRODUÇÃO No final do Paleoproterozóico o Cráton Amazônico foi palco de intenso vulcanismo efusivo e explosivo, identificado como evento Uatumã (Pessoa et al. 1977). Na região centro-sul do Estado do Pará, em área circunvizinha ao município de São Félix do Xingu, no âmbito da Província Mineral de Carajás, este vulcanismo constituiu derrames de lavas traquibasáltica, andesito-basáltica, traquiandesítica, andesítica, dacítica, traquítica e riolítica, e depósitos de fluxo piroclástico, representados por tufos de cristais e vítreo máficos, vítreos félsicos, brecha félsica e brechas polimíticas maciças, as quais se encontram reunidas, respectivamente, nas Formações Sobreiro (FS) e Iriri (FI), do Grupo Uatumã (Macambira \& Vale 1997).

Nas duas últimas décadas essas seqüências vulcânicas foram tema de investigações em escala regional (1:250000), com diferentes enfoques (ex., Macambira \& Vale 1997, Teixeira et al. 2002a, Fernandes 2005). Entretanto, estudos de detalhe voltados para a caracterização petrográfica e geoquímica destes vulcanitos, bem como debates sobre a sua importância na evolução do Cráton Amazônico, são escassos e/ou pouco aprofundados.

Desta forma, buscando preencher essas lacunas, este trabalho objetiva contribuir para o conhecimento desse vulcanismo na região de São Félix do Xingu (Figura 1) e elucidar sua importância para a evolução do Cráton Amazônico como um todo, por meio de novos estudos geológicos e geoquímicos nessas rochas.
CONTEXTO GEOLÓGICO REGIONAL As seqüências vulcânicas pertencentes ao Grupo Uatumã fazem parte da Província Mineral de Carajás, situada no Cráton Amazônico (Almeida et al. 1981), no domínio geocronológico da Província Amazônia Central (Tassinari \& Macambira 1999). Encontramse associadas aos granitóides de 1880 Ma da Suíte Intrusiva Velho Guilherme (Teixeira 1999).

Fernandes (2005) realizou datações $\mathrm{Pb}-\mathrm{Pb}$ em zircão em dacito porfirítico da FS e obteve para quatro cristais idade média de $1880 \pm 6 \mathrm{Ma}$, interpretada como aquela de cristalização. Pórfiros graníticos associados à FI revelaram idade em torno de 1880 Ma (Paiva Júnior 2004, Cruz 2004), a qual foi estendida a esta unidade.

Em parte da área de ocorrência desses vulcanitos atuaram diversos eventos termo-tectônicos desenvolvidos no Arqueano e no Proterozóico, os quais estão testemunhados por transformações mineralógicas e elementos estruturais impressos em unidades lito-estratigráficas do embasamento arqueano pertencente ao Terreno Granito-Greenstone do Sul do Pará e ao Cinturão de Cisalhamento Itacaiúnas (Araújo et al. 1988).

MATERIAIS E MÉTODOS O estudo petrográfico, mesoscópico e microscópico, visando caracterizar as rochas do Grupo Uatumã, foi realizado em 50 amostras, o qual envolveu

1 - Grupo de Pesquisa Petrologia de Granitóides (GPPG) - Centro de Geociências - UFPA. Instituto de Geociências da Universidade de São Paulo. CEP 05508-080. São Paulo, São Paulo, Brasil. FAX: +55(11)3091-4023, cmdf@usp.br

2 - Programa de Pós-graduação em Mineralogia e Petrologia do Instituto de Geociências - USP.

3 - Departamento de Geoquímica e Petrologia do Centro de Geociências - UFPA. Centro de Geociências da Universidade Federal do Pará, Caixa Postal 1611. CEP 66075-900. Belém, Pará, Brasil. FAX: +55(91)3201-7609, lamarão@ufpa.br 


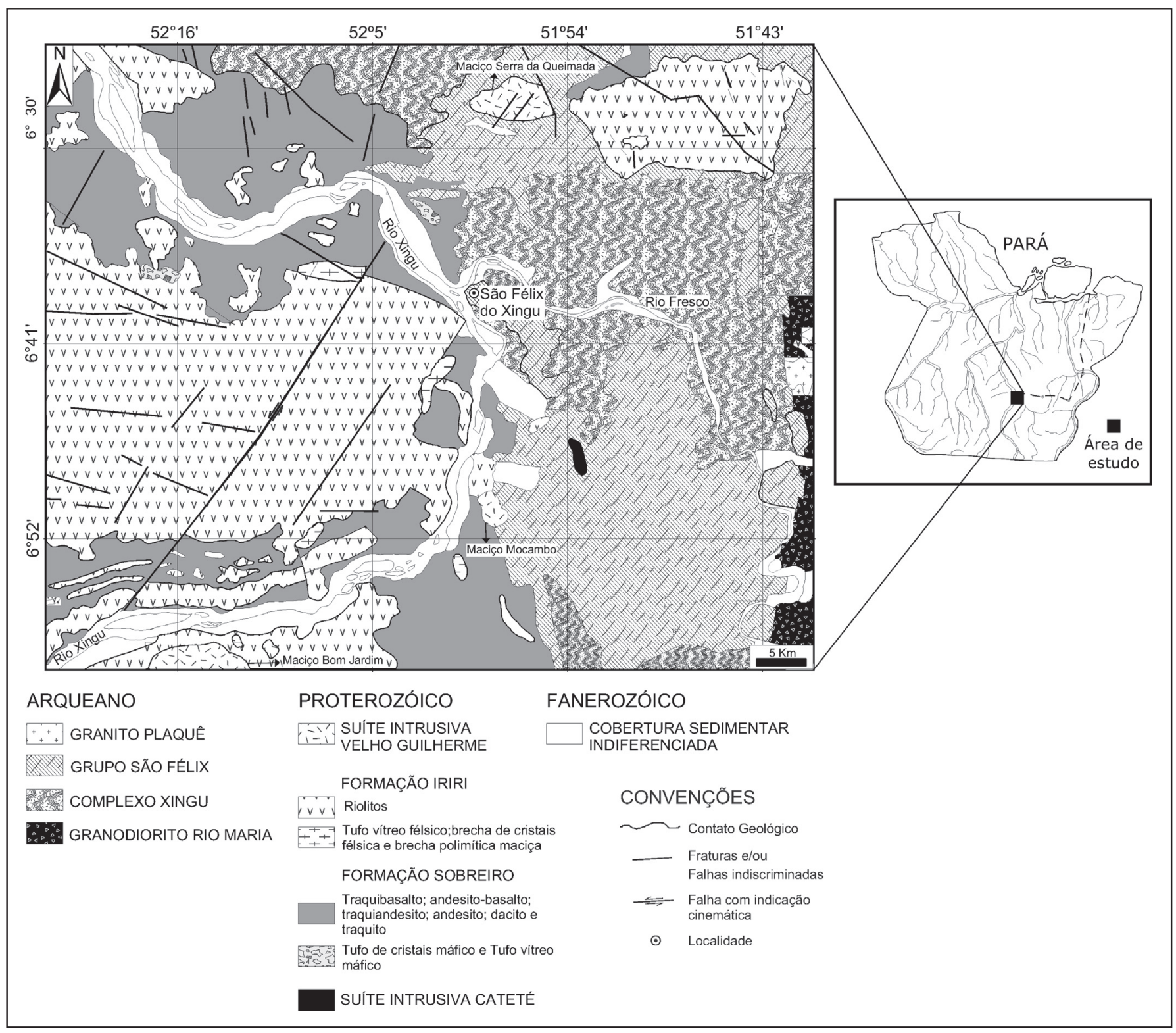

Figura 1 - Mapa geológico da região de São Félix do Xingu com base na Folha SB-22-Y-B (modificado de Fernandes 2005).

o reconhecimento das fases minerais, suas relações de contato, formas e dimensões, a presença de inclusões, a identificação dos intercrescimentos (exsolução e substituição), das estruturas (se deformadas ou não), bem como as relações de equilíbrio entre as fases presentes. Também foi importante a caracterização das paragêneses magmáticas e hidrotermais, o estado de alteração, além da identificação de cristais e fragmentos líticos de origem piroclástica.

As análises químicas em rocha total de elementos maiores, menores e traço foram realizadas no Acme Analytical Laboratories Ltd (Vancouver, CANADÁ). A abertura das amostras foi feita por fusão. Os elementos maiores e menores foram medidos por ICP-ES (Inductively Coupled Plasma-Emission Spectrometry) e os traço, incluindo elementos terras raras, por ICP-MS (Inductively Coupled Plasma-Mass Spectrometry). FeO foi dosado por via úmida no Laboratório de Análises Químicas do Centro de Geociências da UFPa.

GEOLOGIA E PETROGRAFIA DOS VULCANITOS ESTUDADOS A FS na região de São Félix do Xingu ocorre ao longo de ambas as margens do Rio Xingu e, subordinadamente, à nordeste da área de estudo (Figura 1). É caracterizada por topografia arrasada, com raras elevações, onde se desenvolve drenagem com padrão dendrítico. Nesta área aparecem derrames de lavas aflorantes em lajedos e, subordinadamente, na forma blocos isolados, com evidente foliação de fluxo. A noroeste da área nesta mesma unidade foram também identificados blocos de tufos que sugerem terem sido originadas a partir de vulcanismo explosivo seguido por fluxo piroclástico (Fernandes 2005).

Por sua vez, a FI aparece sob a forma de blocos espaçados associados a domos vulcânicos de extensões quilométricas, com até $500 \mathrm{~m}$ de altitude. O mais proeminente deles ocorre na "segunda grande volta do Xingu", sudoeste da área de estudo (Figura 1). Trata-se de uma serra com vertentes íngremes. Em alguns deles, a ocorrência de tufos e brecha polimítica maciça (Fernandes 2005) sugere a presença de vulcanismo explosivo. Comumente diques de granitos porfiríticos cortam esta unidade (Cruz 2004, Paiva Júnior 2004), e podem estar relacionados à colocação dos maciços graníticos da Suíte Intrusiva Velho Guilherme. Ambas as unidades encontram-se sobrepostas às rochas gnáissicas e gabróicas do Complexo Xingu e às metavulcânicas máficas do Grupo São Félix (Macambira \& Vale 1997). 
Formação Sobreiro Os depósitos coerentes da FS apresentam aspecto maciço, texturas porfirítica e afanítica com coloração variável desde negra, cinza-escuro, púrpura-escuro a verde-escuro. Composicionalmente são traquibaltos, andesito-basaltos, traquiandesitos, andesitos, dacitos e traquitos. Ao microscópio, exibem textura microporfirítica a microglomeroporfirítica, ora holocristalina ora hipocristalina, com microfenocristais de clinopiroxênio, anfibólio e, subordinadamente, plagioclásio, imersos em matriz criptocristalina ou microlítica. Esta última é formada por micrólitos de plagioclásio de granulação fina. Subordinadamente ocorrem litotipos afíricos constituídos por pseudoesferulitos dos tipos "esférico", "leque" e "nó de gravata" formados, provavelmente, pelo intercrescimento de fibras de piroxênio, posteriormente substituídas por anfibólio. Sericita, clorita, epídoto, carbonatos e minerais opacos são as fases secundárias. Localmente, em alguns litotipos, ocorrem amídalas esféricas à sub-esféricas que, a partir do núcleo, são preenchidas por clorita, quartzo, epídoto, carbonatos e, localmente, opacos. Zircão, apatita e minerais opacos ocorrem como principais acessórios primários (Fernandes 2005).

Os depósitos piroclásticos, representados por tufos vítreos e de cristais e brechas polimíticas, que também fazem parte da FS, apresentam grande quantidade de cristais e fragmentos mal selecionados de quartzo, plagioclásio, clinopiroxênio e anfibólio, bem como fragmentos líticos de composição intermediária e vítrea (glassy shards), além de pumices, suportados por matriz vitrofírica. Nessas rochas piroclásticas, localmente, ocorrem fraturas, as quais estão preenchidas por minerais hidrotermais como quartzo, epídoto, clorita e, em menor proporção, carbonatos. Esses mesmos minerais desenvolvem-se também como produtos da alteração hidrotermal pervasiva que afetou essas rochas em diferentes graus (Fernandes 2005).

Formação Iriri As lavas que constituem a FI mostram também aspecto maciço, texturas porfirítica e afanítica, de composição exclusivamente riolítica, exibindo coloração rosa-claro, rosa-avermelhado e rosa-escuro. As variedades porfiríticas ostentam fenocristais milimétricos de quartzo, plagioclásio e feldspato potássico envoltos por matriz afanítica. Ao microscópio mostram textura porfirítica, ora holocristalina ora hipocristalina, e matriz felsofírica (mosaico de quartzo e feldspato potássico), criptocristalina, esferulítica e, localmente, granofírica. Clorita, epídoto, carbonatos e sericita constituem os minerais secundários. Biotita figura subordinadamente como mineral varietal. Zircão e minerais opacos são as principais fases acessórias primárias (Fernandes 2005).

Em relação aos termos piroclásticos nessa unidade, estão presentes tufos de cristais e brechas caracterizados por cristais e fragmentos de cristais de anfibólio e, subordinadamente, de plagioclásio. Fragmentos líticos de composições félsica e intermediária suportados por matriz vitrofírica também são encontrados. Em menor proporção ocorrem brechas polimíticas maciças contendo fragmentos centimétricos de várias litologias (andesítico, riolítico e piroclástico) imersos em matriz vitrofírica. Sericita, carbonatos e minerais opacos figuram como fases secundárias (Fernandes 2005).

CLASSIFICAÇÃO E GEOQUÍMICA Neste trabalho utilizou-se a geoquímica de rocha total para melhor classificar os vulcanitos em tela, devido a impossibilidade da realização de análise modal, face às características texturais dos litotipos.

As composições químicas de 20 amostras das unidades em questão, bem como razões entre óxidos maiores e elementos traço, são mostradas na Tabela 1.

AFS consiste de uma série magmática expandida, justificada por teores de sílica variando entre 47,43 e $63,22 \%$ e razões $\mathrm{K}_{2} \mathrm{O} /$
$\mathrm{Na}_{2} \mathrm{O}$ relativamente baixas (média de 0,79 , desconsiderando-se os valores anômalos das amostras NN-GM-10B e NN-GM-53; Tabela 1). Por sua vez, a FI mostra um intervalo mais restrito nos teores de $\mathrm{SiO}_{2}$, variando entre 72,64 e 76,96\% além de razões $\mathrm{K}_{2} \mathrm{O} / \mathrm{Na}_{2} \mathrm{O}$ comparativamente mais altas (média de 2,29; Tabela 1) que a FS. Tais dados químicos quando lançados no diagrama discriminante TAS (Le Maitre 2002) permitem identificar dois grupos distintos de rochas (Figura 2). No primeiro, verifica-se a existência de uma série saturada em sílica, representada por traquibasalto, traquiandesito e traquito e outra supersaturada em sílica, formada de andesito-basáltico, andesito e dacito. Tal comportamento será discutido mais adiante.

Por sua vez, a FI mostra composição exclusivamente riolítica e supersaturada em sílica. Semelhantemente aos resultados analíticos da FS, também aqueles da FI plotam predominantemente no campo subalcalino de Irvine \& Baragar (1971), no entanto, a maioria das amostras apresenta teores de álcalis acima de 5\% (série saturada) e próximos do limite com o campo alcalino, sugerindo, em uma primeira análise, um caráter mais transicional para essas unidades. A divisão e o caráter transicional também estão claramente assinalados no estudo de correlação de óxidos de elementos maiores e traço, apresentados mais adiante.

Quando lançadas no diagrama AFM (Irvine \& Baragar 1971), as amostras da FS mostram uma dispersão dos pontos (Figura 3) dentro do campo cálcico-alcalino, não definindo o trend típico dessa série que se traduz pelo aumento progressivo de álcalis acompanhado por razões $\mathrm{FeO} * / \mathrm{MgO}$ praticamente constantes. Diferentemente, os resultados analíticos da FI agrupam-se próximo ao vértice $\mathrm{Na}_{2} \mathrm{O}+\mathrm{K}_{2} \mathrm{O}$ desse diagrama (Figura 3 ).

Com relação ao Índice de Saturação em Alumina (ISA; Figura 4), as rochas das FS são metaluminosas com valores de A/ CNK variando de 0,6 a 0,9, apresentando apenas uma amostra no campo peraluminoso, com razão $\mathrm{A} / \mathrm{CNK}$ igual a 1,05 . Por sua vez, as rochas da FI são dominantemente peraluminosas, com A/CNK variando de 1,1 a 1,2, embora duas amostras incidam no campo metaluminoso, mas com valores de $\mathrm{A} / \mathrm{CNK}$ próximos de 1, devendo-se frisar que estas amostras representam os termos menos evoluídos deste grupo, com teores de $\mathrm{CaO}$ acima de $1 \%$ (Tabela 1$)$.

Conforme mostrado na Figura 5, as Formações Sobreiro e Iriri revelam um gap entre os seus litotipos, representado por diferenças composicionais e por trends não-contínuos dos elementos maiores em relação ao $\mathrm{SiO}_{2}$ utilizado como índice de diferenciação. Embora haja uma dispersão de pontos nos diagramas, verifica-se que com o aumento progressivo deste índice, há uma diminuição nos conteúdos de $\mathrm{MgO}, \mathrm{CaO}, \mathrm{TiO}_{2}, \mathrm{Fe}_{2} \mathrm{O}_{3}$ e $\mathrm{MnO}$, sobretudo nas rochas de composição mais básica e intermediária da FS, ao passo que os riolitos da FI mostram uma correlação negativa com o $\mathrm{CaO}, \mathrm{TiO}_{2}, \mathrm{Al}_{2} \mathrm{O}_{3}, \mathrm{MnO}$ e $\mathrm{K}_{2} \mathrm{O}$ e tendem a se agrupar nesses diagramas, em decorrência da pouca variação de $\mathrm{SiO}_{2}$. Nítida correlação positiva é observada com o $\mathrm{K}_{2} \mathrm{O}$ nas rochas da FS, evidenciando também as duas séries identificadas na Figura 2 (linhas pontilhadas). $\mathrm{Al}_{2} \mathrm{O}_{3}$ mostra uma correlação positiva nas rochas da FS, exceto o traquibasalto (amostra NNGM-10B), e uma correlação negativa entre os termos da FI, o que pode ser explicado pela influência de clinopiroxênio na evolução dos vulcanitos FS e feldspato potássico na FI. Correlação positiva com sílica também é registrada nas razões $\mathrm{K}_{2} \mathrm{O} / \mathrm{Na}_{2} \mathrm{O}$ de ambas as unidades. A aparente coincidência entre os trends de ambas as unidades em alguns diagramas de correlação pode ser explicada pelo efeito da soma constante, pormenorizado por Rollinson (1993).

O diagrama da figura 6a mostra o campo de andesitos cálcico-alcalinos normais, alguns trends definidos por séries plutônicas cálcico-alcalinas conhecidas, bem como a situação dos pontos respresentativos da FS (Macambira \& Vale 1997). As 


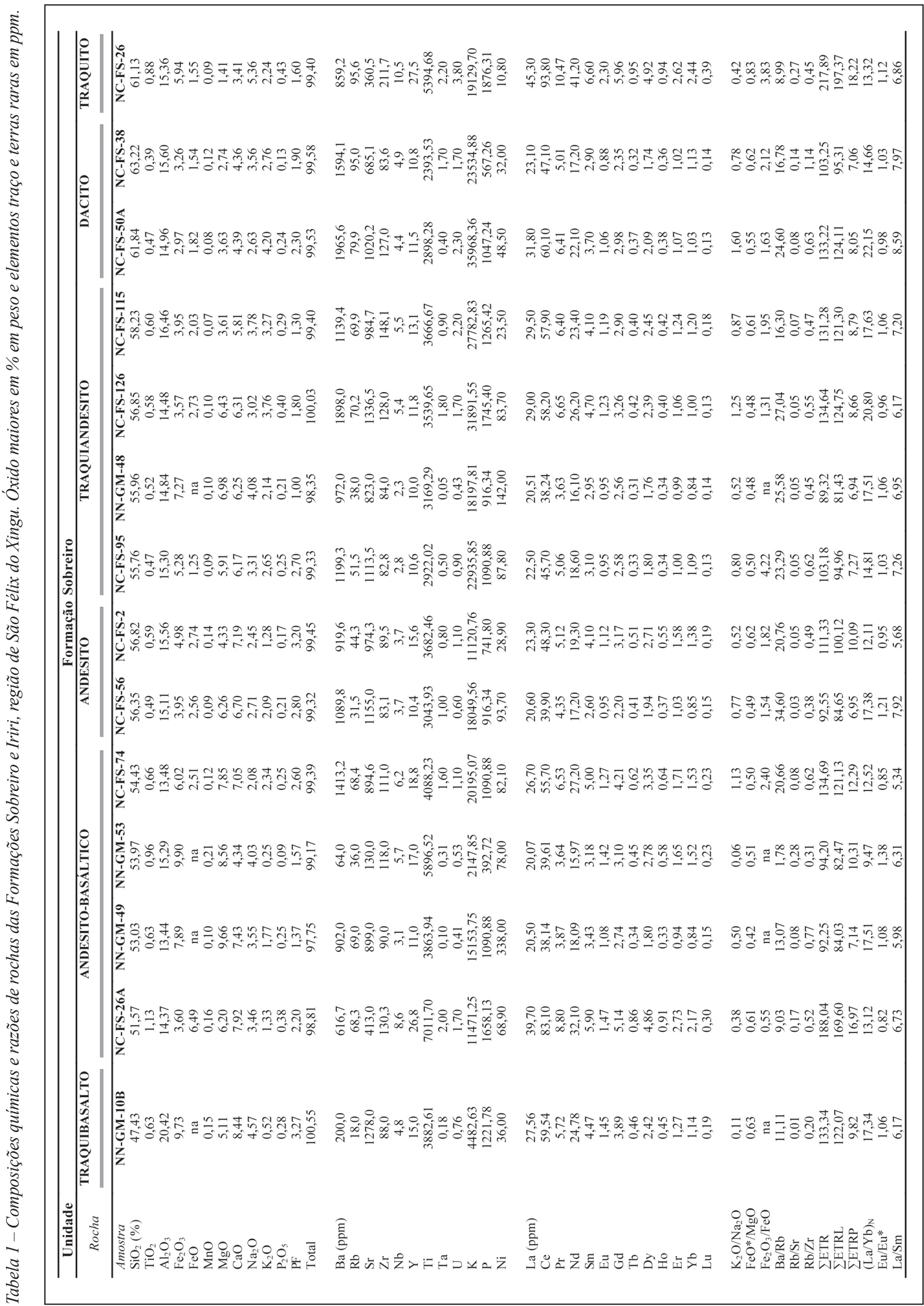




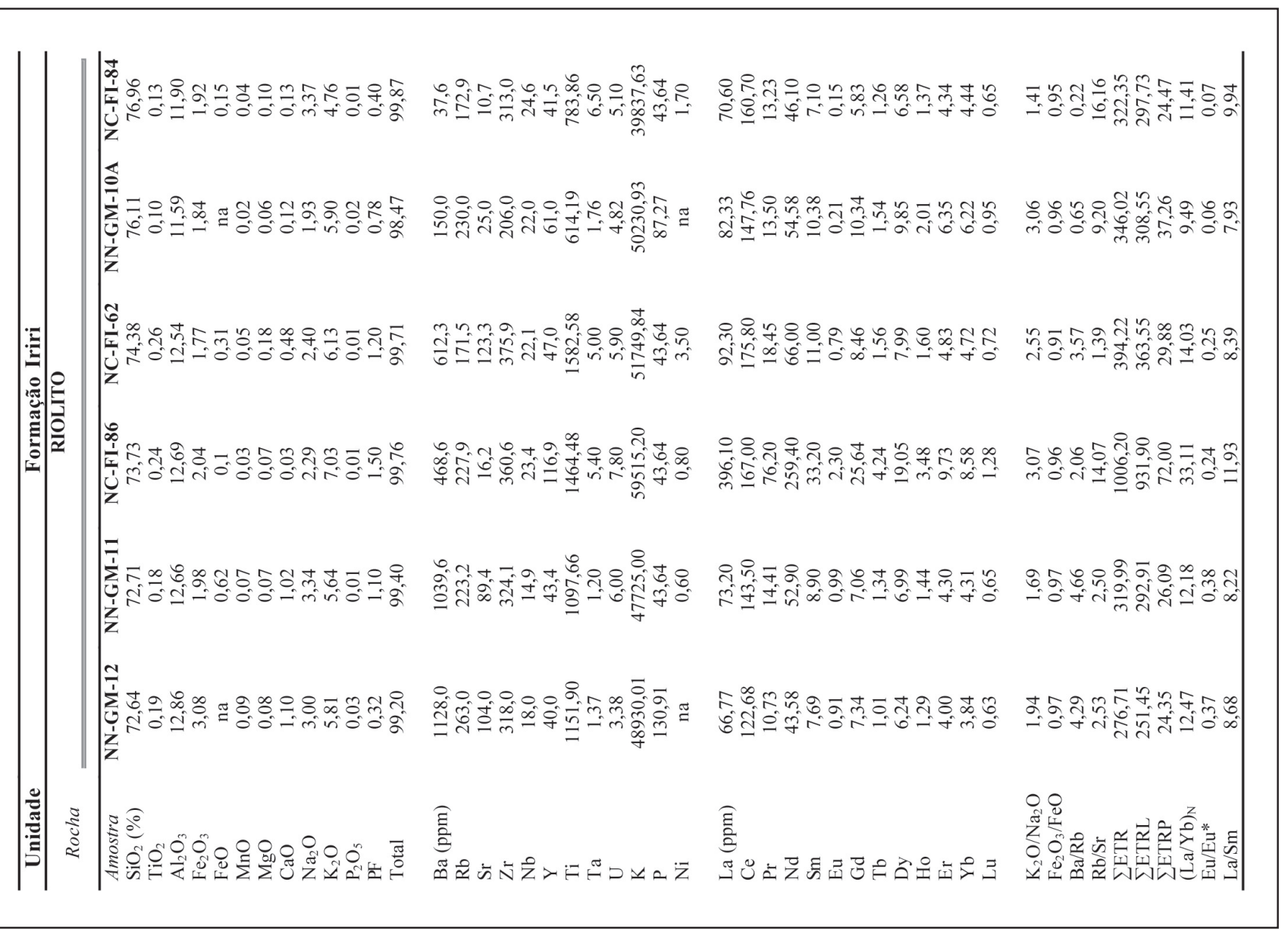

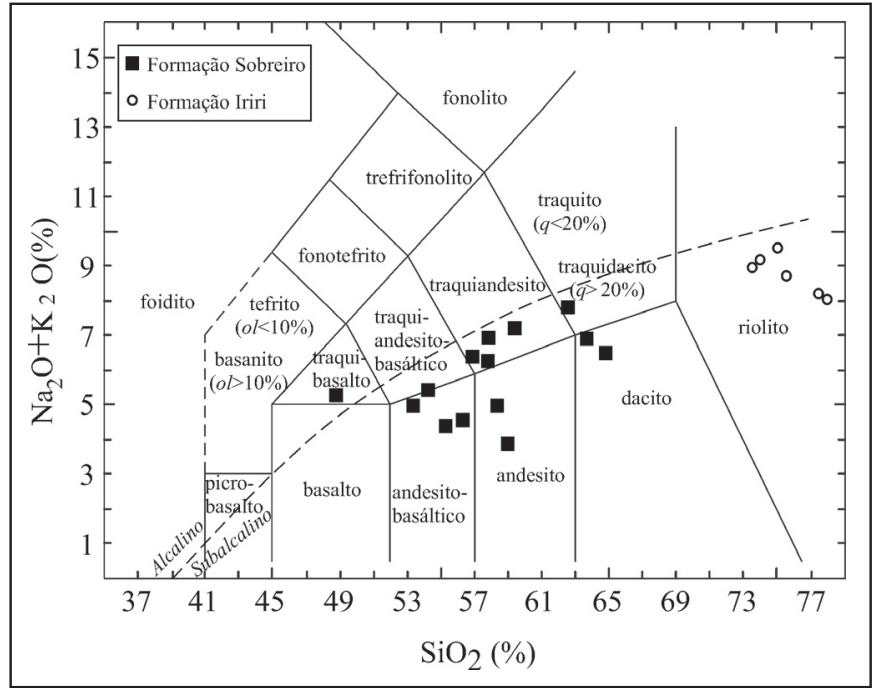

Figura 2 - Diagrama TAS (Le Maitre 2002) para as rochas vulcânicas em estudo. A linha tracejada que separa os campos das séries de rochas alcalinas e subalcalinas é de Irvine \& Baragar (1971).

rochas da FS sugerem a existência de dois trends principais, coincidentes com aqueles definidos na Figura 2, a saber: a) andesito-basáltico - andesito - dacito, seguindo o comportamento dos andesitos cálcico-alcalinos típicos (índice de alcalinidade em torno de $58 \%$ ) e b) traquibasalto - traquiandesito - traquito, aproximando-se mais das séries geoquímicas álcali-cálcicas

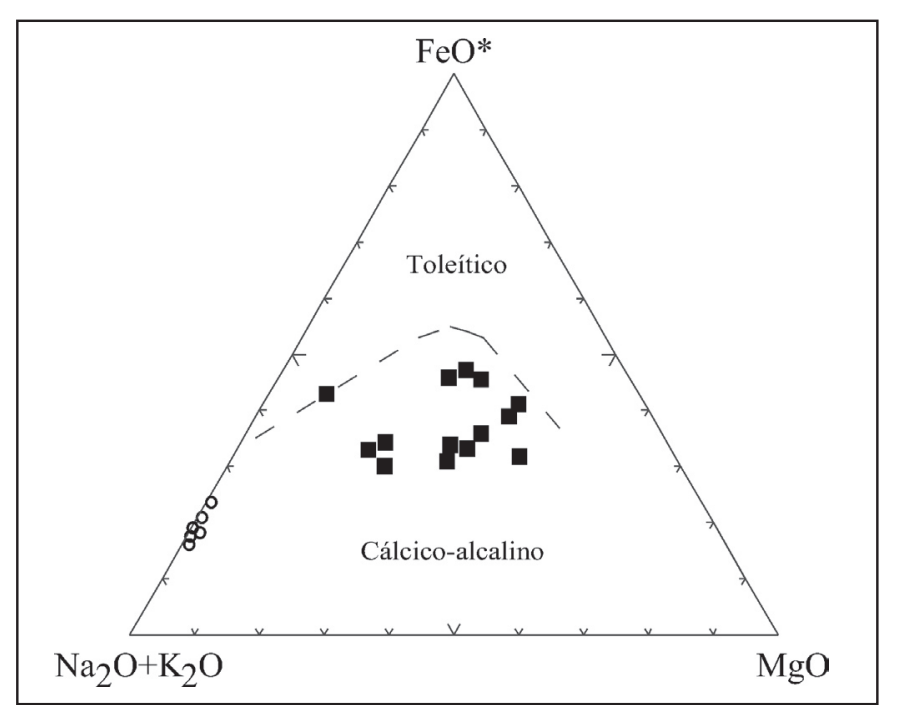

Figura 3 -Diagrama AFM (Irvine \& Baragar 1971) para as rochas vulcânicas em estudo. Símbolos conforme os da figura 2.

(índice de alcalinidade em torno de 55\%). Contudo, essa maior maturidade da série saturada pode ser aparente, pois se admite idade de cristalização em torno de 1,88 Ga para a Formação Sobreiro (Macambira \& Vale 1997, Teixeira et al. 2002b, Fernandes 2005).

$\mathrm{Na}$ Figura $6 \mathrm{~b}$, as rochas da FS mostram conteúdos variados de $\mathrm{K}_{2} \mathrm{O}$ e distribuem-se dominantemente nos campos de médio$\mathrm{K}$ e alto-K, com uma amostra no campo baixo-K e outras duas 


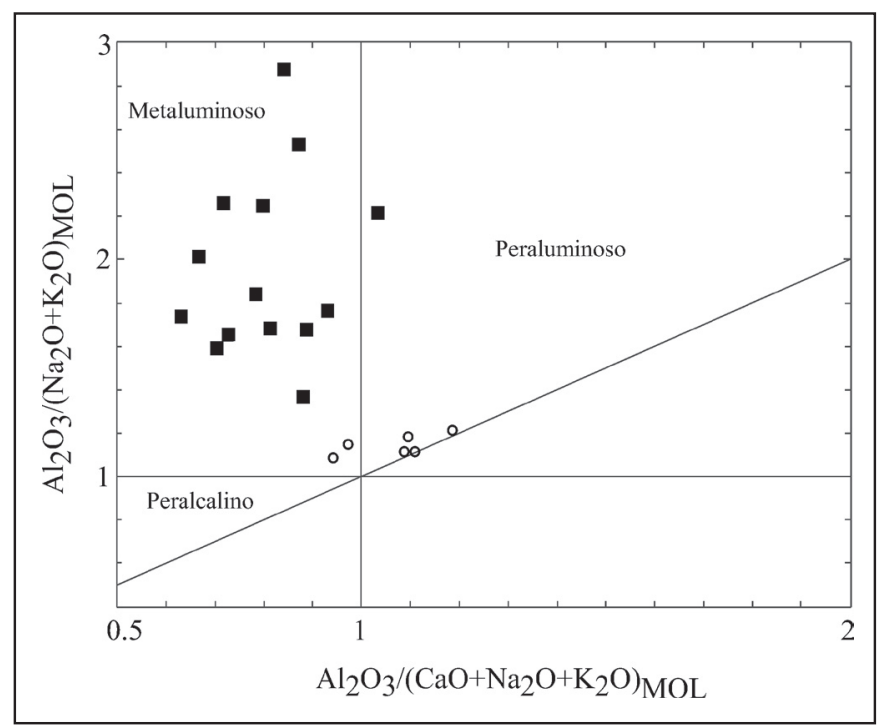

Figura 4-Diagrama A/NK versus A/CNK de Maniar \& Piccoli (1989) para as rochas das Formações Sobreiro e Iriri. Símbolos conforme os da figura 2.

atingindo o campo shoshonítico, semelhantes aos resultados obtidos por Macambira \& Vale (1997). Nota-se que as duas tendências identificadas na Figura 6a também são bem evidentes. Esse comportamento, em uma primeira análise, não define o trend típico de uma série cálcico-alcalina, a qual deveria evoluir predominantemente dentro de um campo. No entanto, processos de fusão parcial de uma fonte comum em diferentes graus ou contaminação crustal podem gerar este trend (Wilson 1989). A remobilização de álcalis, oriunda de alteração hidrotermal pervasiva superimposta também pode ter contribuído. Morrison (1980) relaciona essa forte inclinação, além de outras características geoquímicas, a séries tipicamente shoshoníticas. A presença de fases de dimensões diminutas portadoras de potássio associadas aos micrólitos de plagioclásio na matriz, dificilmente reconhecidas na microscopia ótica convencional, bem como a ocorrência de matriz criptocristalina, podem ser os responsáveis pelo elevado conteúdo de $\mathrm{K}_{2} \mathrm{O}$ presente nesses vulcanitos.

No diagrama $\mathrm{Rb}-(\mathrm{Y}+\mathrm{Nb})$ de Pearce et al. (1984), as rochas da FS plotam no campo de granitos de arco vulcânico (VAG) e as da FI no de intraplaca (WPG), com os seus termos menos evoluídos incidindo na divisa entre os dois campos (Figura 7). Este método de determinação de ambientes tectônicos não é, por si só, decisivo. Vários autores demonstraram que há correlações, bem como ambigüidades, entre assinatura geoquímica e ambiente tectônico (ex., Förster et al. 1997). No caso em estudo, grande parte das rochas da FI incide no campo pós-colisional sugerido por Pearce (1996), o que pode simplesmente indicar transição de uma série cálcico-alcalina para alcalina (Barbarin 1999) ou aumento na maturidade do arco (Brown et al. 1984). Portanto, este comportamento deve ser acompanhado por outros tipos de informações que possam auxiliar na caracterização da paleoambiência tectônica nas quais as rochas foram formadas.

$\mathrm{Na}$ Figura 8 são apresentados os trends definidos por alguns elementos compatíveis e incompatíveis, bem como as razões entre eles. Constata-se que as rochas da FI possuem razões $\mathrm{Rb} /$ Sr $(1,39$ - 16,16) e teores de Y (40-116,9 ppm), Zr (206-375,9 ppm) e Rb (171,5-263 ppm) superiores aos da FS. Por sua vez, a FS possui razões $\mathrm{Ba} / \mathrm{Rb}$ comparativamente mais elevadas $(8,09$ - 34,6, excluindo-se o valor anômalo da amostra NN-GM-53; Tabela 1). No diagrama Rb versus $\mathrm{Sr}$ são plotados vetores (compilados de Dall Agnol et al. 1999) que indicam as modificações na composição do líquido residual em função do fracionamento das fases minerais indicadas (anfibólio, biotita, plagioclásio, feldspato potássico e clinopiroxênio). Na FS, o aumento de Rb, com o Sr se mantendo praticamente constante, pode ser explicado pela influência simultânea de anfibólio, clinopiroxênio e plagioclásio na seqüência de evolução dos vulcanitos (trend 1 da Figura 8b), a partir do traquibasalto até o dacito. Por outro lado, a FI contém teores de Sr mais elevados nos termos menos evoluídos, o que sugere uma participação acentuada de feldspatos na evolução desta unidade (trend 2 da Figura $8 \mathrm{~b}$ ).

Treuil \& Joron (1975) desenvolveram um modelo quantitativo para identificação de processos de cristalização fracionada e fusão parcial envolvendo elementos traço, utilizando diagrama $\mathrm{La} / \mathrm{Sm}$ versus La. Durante processos de cristalização fracionada as composições de uma série de lavas definem neste diagrama um trend horizontal. Em suítes em que a fusão parcial foi o mecanismo reinante, os pontos definem nítida correlação positiva. Esse alinhamento de pontos não deve ser obtido para outros modelos de geração de magma. As amostras da FS, quando lançadas neste diagrama (Figura 8d), revelam um trend dominantemente vertical, embora deslocamentos horizontais também sejam visualizados, ao passo que as amostras da FI mostram certa dispersão. Em conclusão, esse diagrama sugere que tanto a fusão parcial em diferentes graus, seguida por cristalização fracionada, podem ter participado na geração desses vulcanitos.

No que se referem aos elementos terras raras (ETR), bem como de seus padrões de distribuição normalizados para o condrito C1 de Sun \& McDonough (1989), observa-se nítida diferença entre as duas unidades vulcânicas (Tabela 1; Figura 9). Os vulcanitos da FS exibem teor médio de ETR situado entre 218,21 ppm e 89,44 ppm, enquanto os da FI situam-se entre 1007,48 ppm e 277,31 ppm. Em ambas as unidades os elementos terras raras leves (ETRL) mostram-se enriquecidos em relação aos elementos terras raras pesados (ETRP), desenhando uma inclinação das curvas para a direita. A FS possui maior inclinação nos ETRP, com razão média $(\mathrm{La} / \mathrm{Yb})_{\mathrm{N}}$ situando-se entre $12,11 \mathrm{e}$ 22,15 (excetuando-se o valor anômalo da amostra NN-GM-53) que pode ser explicada pelo fracionamento moderado de fases como hornblenda, clinopiroxênio e zircão. No caso da FI essa inclinação é menos pronunciada, com razão média $(\mathrm{La} / \mathrm{Yb})_{\mathrm{N}}$ mostrando valores entre 9,49 e 12,47 (desconsiderando-se o valor anômalo da amostra NC-FI-86). Em relação ao Eu, os litotipos da FI mostram anomalias negativas acentuadas, representadas por razões $0,06<\mathrm{Eu} / \mathrm{Eu}^{*}<0,38$. Tal fato demonstra a participação importante dos feldspatos, no caso da FI, no fracionamento de Eu, o qual se comportou como compatível durante a fusão/ diferenciação que originou os vulcanitos em estudo, visto que esses minerais têm maior afinidade pelo $\mathrm{Eu}^{2+}$ se comparado aos outros ETR trivalentes (Miller \& Mittlefheld 1982). As rochas da FS, por outro lado, não apresentam anomalias de Eu, e suas razões $\mathrm{Eu} / \mathrm{Eu}^{*}$ situando-se entre 0,82 e 1,38 (Tabela 1). Na FI a amostra NC-FI-86 apresenta, ainda, médio a alto fracionamento dos ETRP, forte enriquecimento dos ETRL e forte fracionamento dos ETR $\left.\left[(\mathrm{La} / \mathrm{Yb})_{\mathrm{N}}=33,13\right)\right]$, comportamento semelhante ao dos riolitos arqueanos tipo F1 de Condie (1976).

Os diagramas de multi-elementos normalizados para o manto primitivo de Wood et al. (1979) também mostram clara distinção entre as duas seqüências em estudo (Figuras 10a e 10b). A FS exibe importantes anomalias negativas em $\mathrm{Ta}, \mathrm{Nb}$ e Ti e anomalias positivas de $\mathrm{Ba}$ e Sr. Por outro lado, os litotipos da FI apresentam fortes anomalias negativas de $\mathrm{Ba}, \mathrm{Nb}, \mathrm{Sr}, \mathrm{P}$ e Ti. Tais anomalias na FI podem ser atribuídas ao fracionamento de feldspatos, provocando o empobrecimento de $\mathrm{Ba}$ e Sr; bem como ao de óxidos de Fe-Ti, contribuindo para a diminuição de Ti. Quando comparados aos granitóides arcos continentais estudados por Brown et al. (1984), apresentados na Figura 10c, 

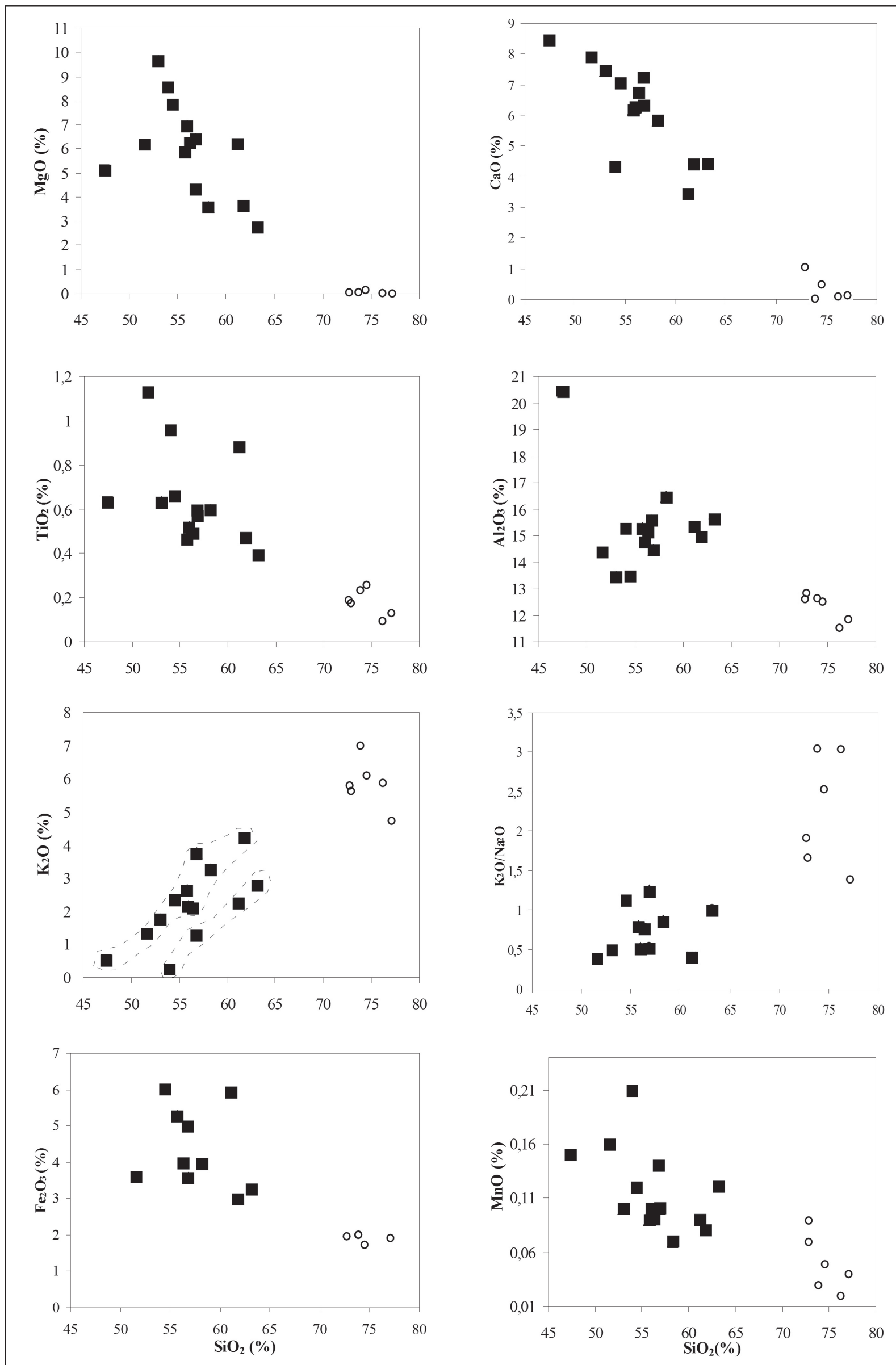

Figura 5 - Diagramas de variação de óxidos de elementos maiores para as rochas das Formações Sobreiro e Iriri. Símbolos conforme os da figura 2. 


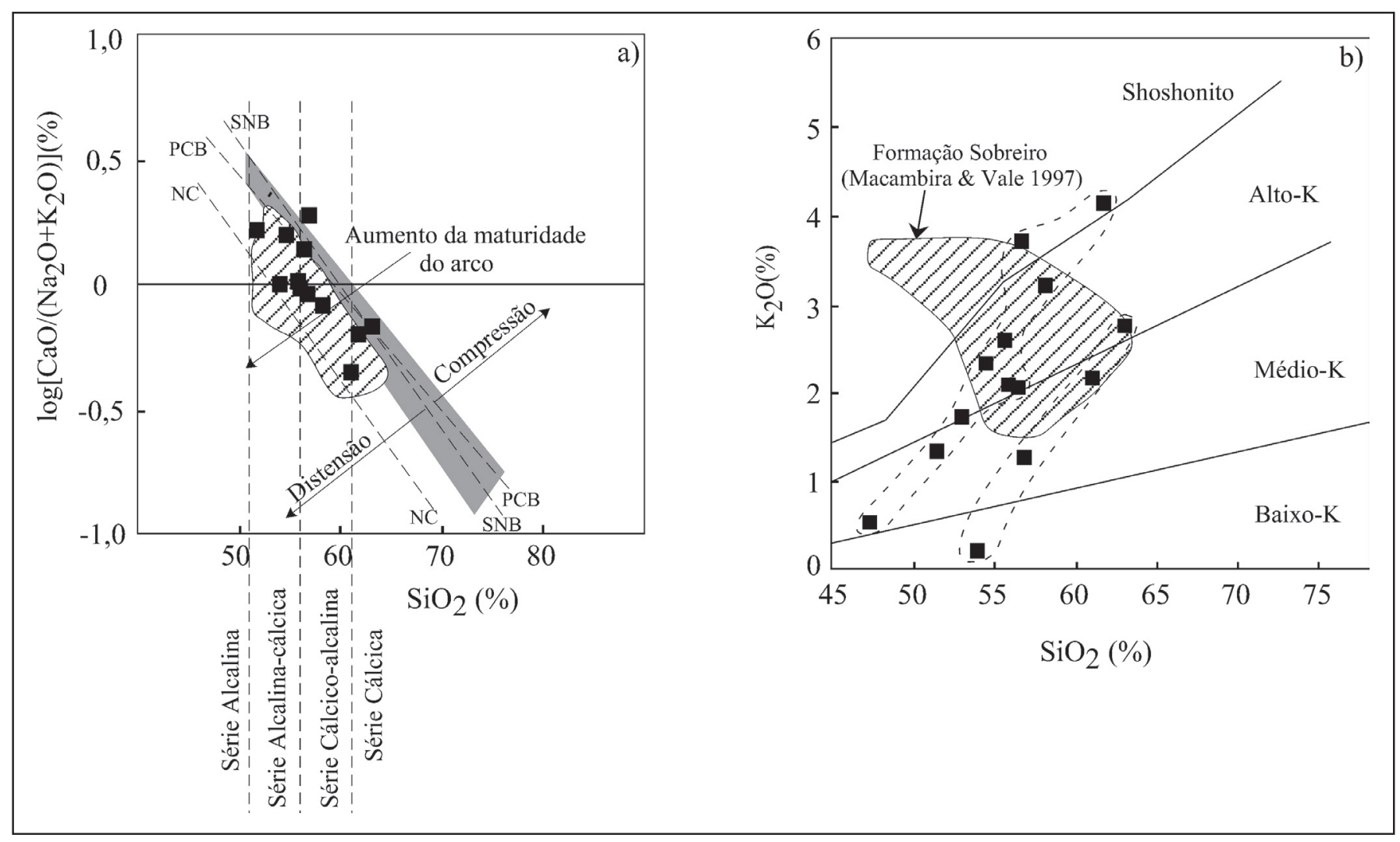

Figura 6 - (a) Diagrama log (CaO/Na $\left.\mathrm{O}_{2} \mathrm{~K}_{2} \mathrm{O}\right)$ versus $\mathrm{SiO}$ (modificado de Brown et al. 1984) para as rochas da Formação Sobreiro. O campo em cinza representa andesitos cálcico-alcalinos normais. O campo hachurado foi definido por Macambira \& Vale (1997) para as rochas da Formação Sobreiro. PCB=Batólito do Peru; SNB=Batólito Serra Nevada e NC=Arco continental Nova Guiné com base em Brown et al. 1984; (b) Diagrama $\mathrm{K}_{2} \mathrm{O}$ versus $\mathrm{SiO}_{2}$ (modificado de Peccerillo \& Taylor 1976) para as rochas das Formações Sobreiro. As linhas pontilhadas indicam as duas séries da Figura 6a. Símbolos conforme os da figura 2.

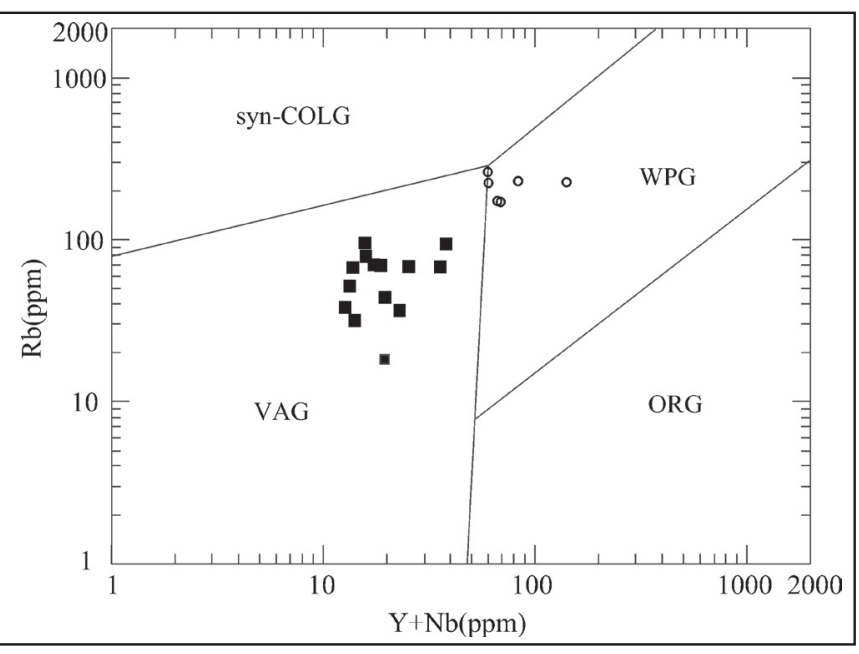

Figura 7 - Diagrama de discriminação tectônica $(Y+N b)$ versus $R b$ de Pearce et al. (1984) para as rochas das Formações Sobreiro e Iriri. Símbolos conforme os da figura 2.

esses padrões sugerem um ambiente transicional entre o final de uma orogênese e início de rift continental, haja vista que ambas as unidades são contemporâneas.

Pearce \& Cann (1973) desenvolveram diagramas que utilizam elementos traço para a determinação do ambiente tectônico de rochas básicas, entre eles o diagrama Ti versus $\mathrm{Zr}$. Neste diagrama, as rochas da FS incidem dominantemente no campo C (Figura 11a), de basaltos cálcico-alcalinos. Os dados de Macambira \& Vale (1997) plotam também neste campo, o que levou esses autores a concluírem que a FS apresenta um caráter dominantemente cálcico-alcalino, corroborando com os resultados obtidos nas Figuras 3 e 6a. Para os litotipos da FI, utilizando-se o diagrama para rochas graníticas $(\mathrm{Zr}+\mathrm{Nb}+\mathrm{Ce}+\mathrm{Y})$ versus $\mathrm{FeO} * \mathrm{MgO}$ de Whalen et al. (1987), se observa uma íntima relação entre essa unidade e os granitos tipo-A da Suíte Intrusiva Velho Guilherme (Figura 11b), que segundo Macambira \& Vale (1997) e Teixeira (1999) são formados em regime extensional intraplaca.

DISCUSSÕES A origem das rochas vulcânicas de afinidade shoshonítica tem sido atribuída a processos associados a margens continentais ativas e zonas de colisão continental, bem como a ambientes não diretamente relacionados com o processo de subducção, isto é, são rochas geradas após o término da subducção. Os shoshonitos estariam ligados às fases tardias do processo de subducção com freqüente desenvolvimento de magmatismo alcalino após a estabilização do arco (Carr \& Fardy 1983). Nardi \& Lima (1985) caracterizaram na região de Lavras do Sul (RS) um magmatismo pluto-vulcânico shoshonítico de aproximadamente $2000 \mathrm{Ma}$, com comportamento geoquímico semelhante ao da FS. Segundo Morrison (1980), que definiu as principais características geoquímicas da série shoshonítica, a FS se enquadra na mesma, por exemplo: a) elas possuem alto teor de álcalis $\left(\mathrm{Na}_{2} \mathrm{O}+\mathrm{K}_{2} \mathrm{O}>5 \%\right)$ na série saturada do TAS; b) exibem forte inclinação positiva do trend geoquímico no diagrama $\mathrm{K}_{2} \mathrm{O}$ versus $\mathrm{SiO}_{2}$, para rochas entre 45 e $60 \%$ de $\mathrm{SiO}_{2}$; c) mostram enriquecimento em $\mathrm{Rb}, \mathrm{Ba}$ e $\mathrm{Sr}$, bem como terras raras leves, 


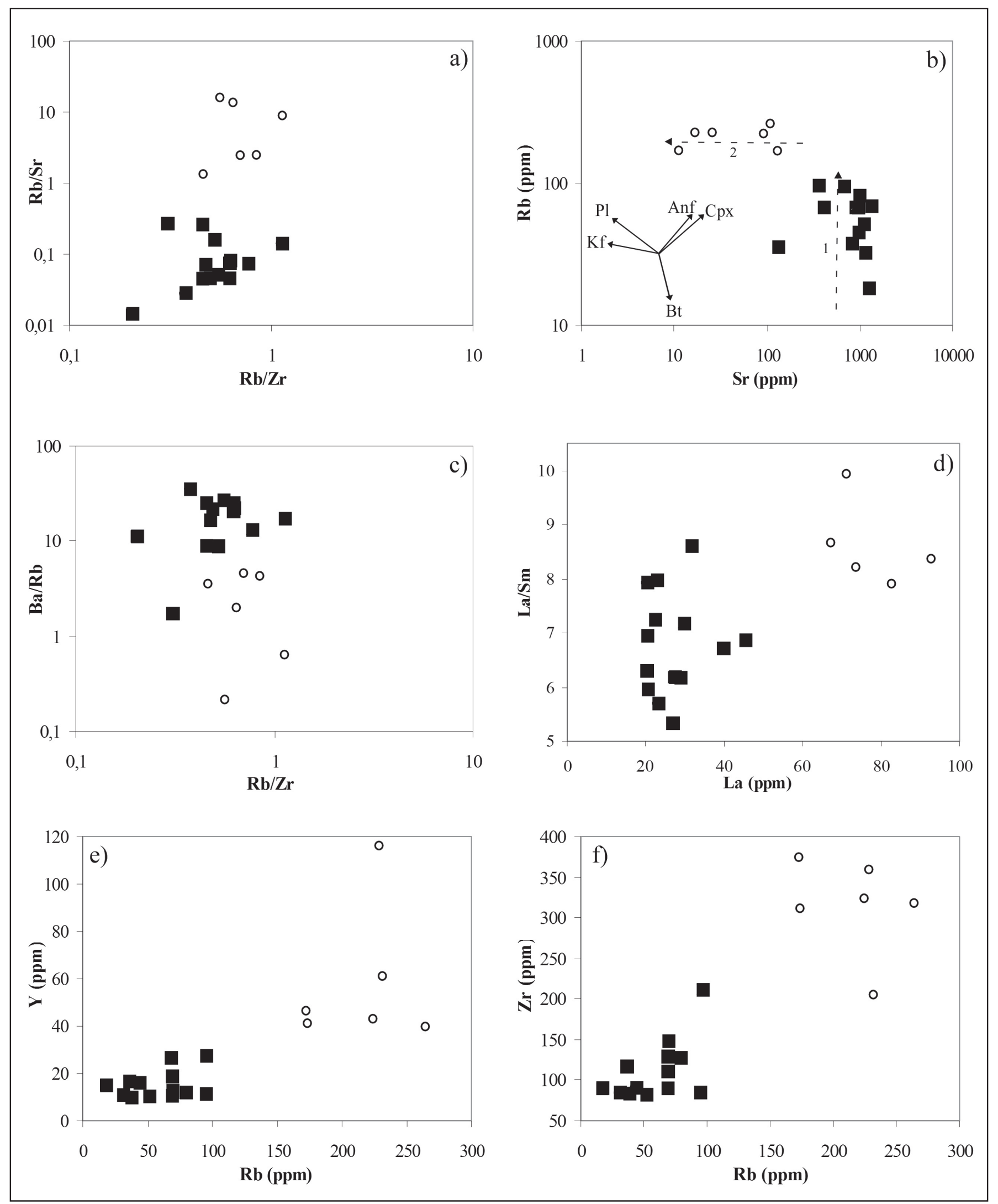

Figura 8 - Diagramas de variação de alguns elementos traço para as rochas das Formações Sobreiro e Iriri. Símbolos conforme os da figura 2.

e empobrecimento em $\mathrm{Ta}$ e $\mathrm{Nb}$ em relação ao manto primitivo de Wood et al. (1979); d) possuem teores de $\mathrm{TiO}_{2}$ menores que $1,3 \%$; e) exibem conteúdo de $\mathrm{Al}_{2} \mathrm{O}_{3}$ predominantemente entre $14 \%$ e $19 \%$ e f) têm relação $\mathrm{Fe}_{2} \mathrm{O}_{3} / \mathrm{FeO}$ maior que 0,5 (Tabe- la 1). Segundo Jakes \& White (1972), os andesitos de margens continentais ativas, tipo andino, desenvolvem com freqüência a associação shoshonítica - cálcico-alcalina rica em potássio, fato 


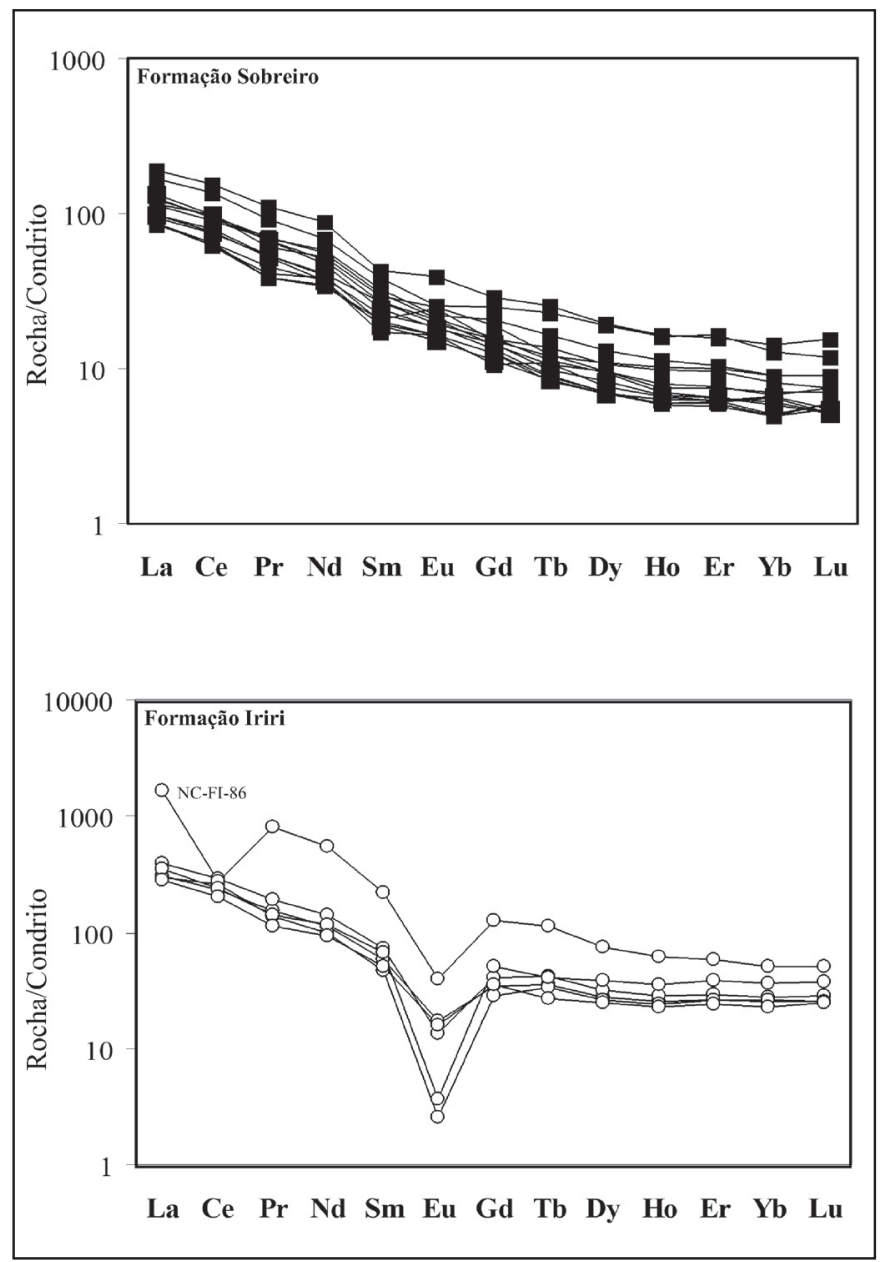

Figura 9-Padrões de ETR normalizados para o condrito C1 de Sun \& McDonough (1989) para as Formações Sobreiro e Iriri. Símbolos conforme os da figura 2.

que também é verificado nas rochas da FS.

Lamarão et al. (2002) propuseram um modelo de evolução para a região de Vila Riozinho, Província Aurífera do Tapajós, com base em dois principais eventos de atividade magmática. $\mathrm{O}$ primeiro ocorrido no intervalo de 2,01 - 197 Ga (Evento Transamazônico) e o segundo em torno de $1880 \mathrm{Ma}$. O evento mais antigo envolveu subducção, gerando o granito São Jorge Antigo e a seqüência vulcânica Vila Riozinho, de aproximadamente 2,0 Ga. Para o evento mais novo duas hipóteses foram levantadas: a) a primeira se baseia em uma segunda etapa de subducção que gerou uma nova série de magmas, associada a arco magmático mais maturo, produzindo os granitos Jardim do Ouro, Maloquinha e São Jorge Jovem, com assinatura geoquímica semelhante a alguns granitos da Suíte Intrusiva Velho Guilherme (Teixeira et al. 2002b) e as vulcânicas da FI; b) a segunda baseia-se na possibilidade do Cráton Amazônico durante o Transamazônico, ter sido palco de processos extensionais, considerado por Lamarão et al. (2002) como sendo de escala continental, marcando o início da tafrogênese que se estendeu até o Mesoproterozóico. Plumas do manto podem ter causado fusões na crosta, produzindo magmas félsicos, que geraram os Granitos Maloquinha e a seqüência vulcânica Moraes Almeida. Os Granitos São Jorge Jovem e Jardim do Ouro podem ter surgido de fontes máficas, ou terem sido resultado da interação de fontes mantélicas e crustais. Sendo assim, a região de Vila Riozinho representaria uma área transicional entre os domínios orogênico e intraplaca.

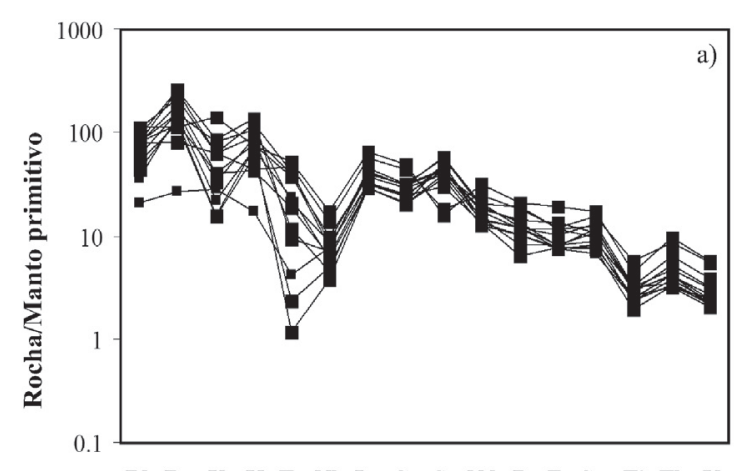

Rb Ba U K Ta Nb La Ce Sr Nd P Zr Sm Ti Tb Y

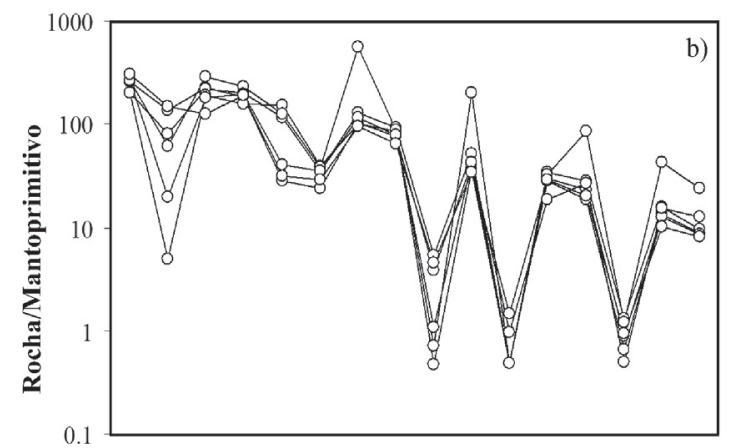

Rb Ba U K Ta Nb La Ce Sr Nd P Zr Sm Ti Tb Y

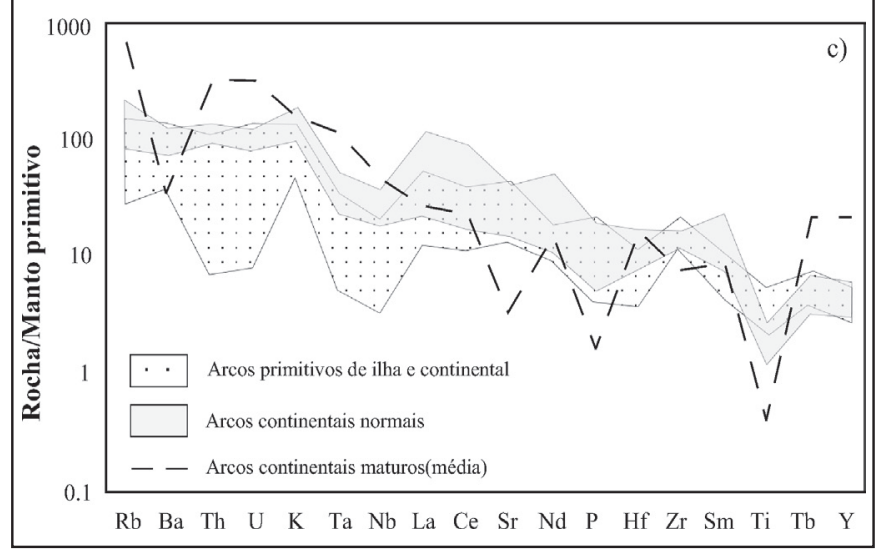

Figura 10 - Diagramas de multi-elementos normalizados para o manto primitivo de Wood et al. (1979): (a) Formação Sobreiro; (b) Formação Iriri e (c) arcos primitivo, normal e maturo de Brown et al. (1984). Símbolos conforme os da figura 2.

Apesar de não conclusivo, a contemporaneidade entre as rochas de $1880 \mathrm{Ma}$ e a Suíte Intrusiva Velho Guilherme, Formações Sobreiro e Iriri e os litotipos formados no evento mais jovem antes referido, indicam uma relação entre eles. Em relação à região do Xingu, a evolução parece ser um misto do que ocorre na região do Tapajós. A idéia do segundo arco magmático mais maturo, porém na fase final de evolução, parece ser compatível com a geração da FS, com caráter transicional entre cálcico-alcalino de alto-K e shoshonítico. Isto pode ser justificado pela interação do magma gerador dessa unidade com outros, durante a fase de ascensão. Esse mecanismo também explicaria a origem das duas séries (saturada e supersaturada) identificadas nesta unidade (Figura 2). Logo em seguida, a tafrogênese que afetou todo o Cráton Amazônico pode ter originado os riolitos da FI, formando a Bacia do Médio Xingu (Macambira \& Vale 1997). 


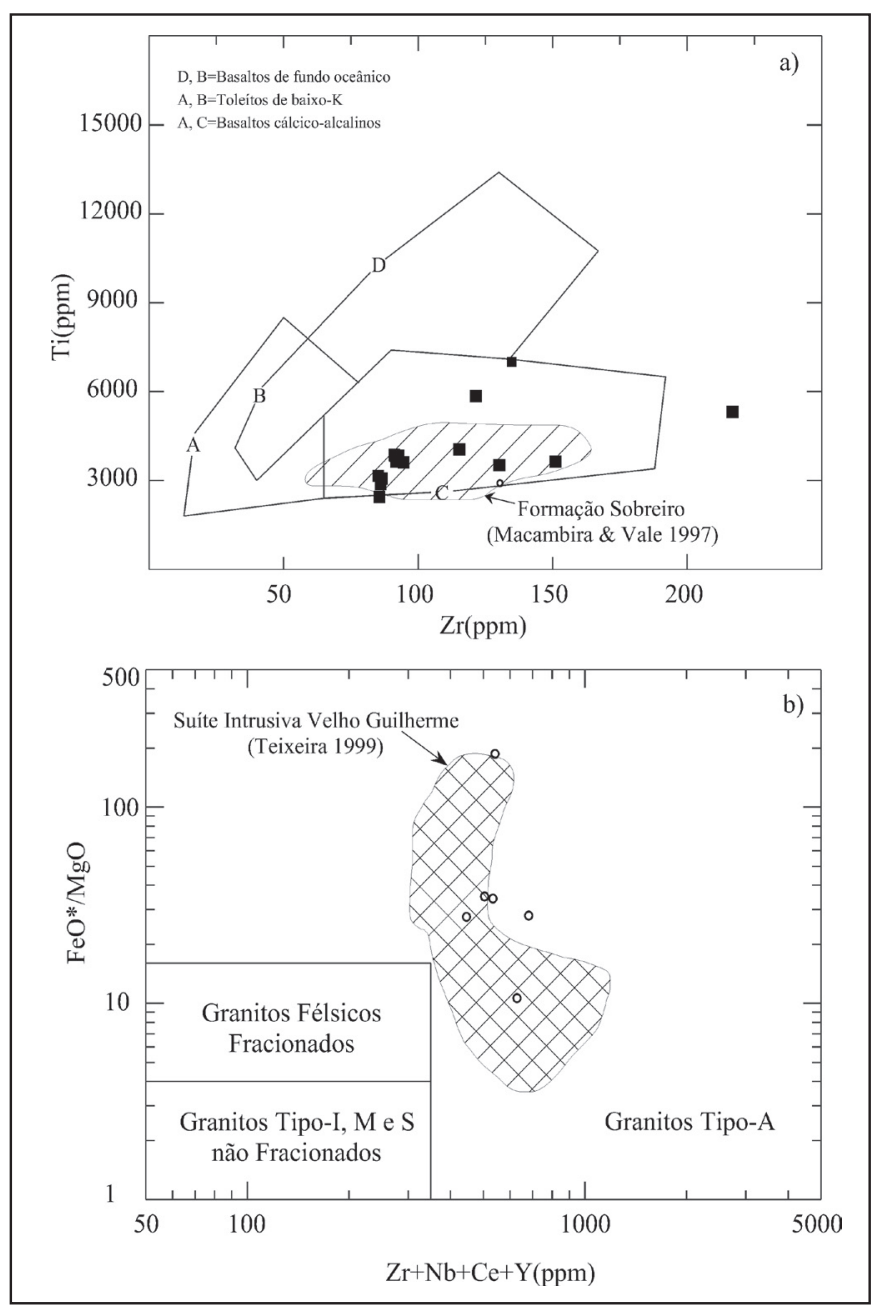

Figura 11 - (a) Diagrama Zr versus Ti de Pearce \& Cann (1973), para as rochas da Formação Sobreiro; (b) Diagrama $\mathrm{Zr}+\mathrm{Nb}+\mathrm{Ce}+\mathrm{Y}$ versus $\mathrm{FeO} * \mathrm{MgO}$ de Whalen et al. (1987) para as rochas da Formação Iriri. Símbolos conforme os da figura 2.
CONCLUSÕES Com base nos dados aqui externados, concluise que a associação de rochas vulcânicas constituintes do Grupo Uatumã na região de São Félix do Xingu é bimodal, oriunda de fontes independentes, com contaminação crustal e alteração hidrotermal superimpostos. Foi formada provavelmente entre final de um evento orogênico e o início de uma fase de rift intracontinental, em aproximadamente $1880 \mathrm{Ma}$, cuja evolução estendeu-se até o Mesoproterozóico. As rochas da FS são metaluminosas, têm natureza cálcico-alcalina transicional de alto-K a shoshonítica e possuem afinidade geoquímica que indica geração em arco vulcânico transicional entre imaturo e maturo. As rochas da FI são metaluminosas a peraluminosas, transicionais entre subalcalinas e alcalinas e têm afinidade geoquímica intraplaca, formada em ambiente distensivo. Tais características permitem uma comparação direta com os dois eventos magmáticos identificados na região do Tapajós, mostrando que o vulcanismo Uatumã, bem como os maciços graníticos a ele associados, têm um papel importante para o entendimento da evolução do Cráton Amazônico como um todo. Contudo, novos dados de campo e modelamentos petrogenéticos são necessários para uma assertiva mais precisa com relação ao paleoambiente tectônico de formação dessas seqüências.

Agradecimentos Os autores deste trabalho agradecem: ao Núcleo PRONEX (103-98/MCT/CNPq-Proc. 66.2103/98-0) do CG/UFPA pelo apoio financeiro nas etapas de campo; ao CNPq, Projeto Magmatismo da Província Mineral de Carajás: processos, colocação e implicações para a evolução crustal (Processo 476075/2003-3) pelo apoio financeiro nas análises químicas em rocha total, e pela concessão da bolsa de mestrado ao primeiro autor; ao químico Natalino Valente do CG/UFPA pelas análises de FeO; à CVRD - Tucumã e aos geólogos Carlos Heron Tavares Dias e Bá Amadou pela concessão da base logística, bem como aos técnicos Walter Luiz Brito da Silva e Roberto Messias pelo apoio na primeira etapa de campo; ao Curso de Pós-graduação em Geoquímica e Petrologia da UFPA e ao professor Dr. Caetano Juliani da Universidade de São Paulo pelas sugestões e críticas na revisão do texto. Este trabalho é uma contribuição para o projeto PRONEX (103-98/MCT/CNPq-Proc. 66.2103/98-0) para o conhecimento geológico do Cráton Amazônico.

\section{Referências}

Almeida F.F.M., Hasui Y., Brito Neves B.B. de, Fuck R.A. 1981. Brazilian Structural Provinces: an introduction. Earth Sci. Rev., 17:1-29.

Araújo O.J.B., Maia R.G.N., Jorge João X.S., Costa J.B.S. 1988. A megaestruturação da Serra dos Carajás. In: SBG, Congr. Latinoamer. Geol., 7, Belém, Anais, v. 1, p. 324-338.

Barbarin B. 1999. A review of the relationships between granitoid types, their origins and their geodynamic environments. Lithos, 46:605626

Brown G.C., Thorpe R.S., Webb P.C. 1984. The geochemical characteristics of granitoids in contrasting arcs and comments on magma sources. J. Geol. Soc. London. 141:413-426.

Carr P.P. \& Fardy J.J. 1983. REE geochemistry of Late Permian shoshonitic lavas from the Sydney Basin, New South Wales, Australia. Chem. Geol, 43:187-201

Condie K.C. 1976. Plate Tectonics and Crustal Evolution. Pergamon Press, Elmsford,289 p.

Cruz V.L. 2004. Petrografia e geocronologia Pb-Pb do Granito Pórfiro de Vila Santa Rosa, região de São Félix do Xingu, Província Mineral de Carajás. In: UFPA, Seminário de Iniciação Científica da UFPa, 15, Belém, Atas, v.1, p. 75.

Dall Agnol R., Costi H.T., Leite A.A. da, Magalhães M.S. de, Teixeira N.P. 1999. Rapakivi granites from Brazil and adjacent areas. Prec. Res., 95:9-39.
Fernandes C.M.D. 2005. Geologia, Geoquímica e Geocronologia das vulcânicas do Grupo Uatumã, região de São Félix do Xingu (PA), Província Mineral de Carajás. Dissertação de Mestrado, Centro de Geociências, Universidade Federal do Pará, 136 p.

Förster H.J., Tischendorf G., Trumbull R.B. 1997. An evaluation of the $\mathrm{Rb}$ vs. $(\mathrm{Y}+\mathrm{Nb})$ discrimination diagram to infer tectonic setting of silicic igneous rocks. Lithos, 40:261-293.

Irvine T.N. \& Baragar W.R.A. 1971. A guide to the chemical classification of the common volcanic rocks. Can. J. Earth. Sci., 8:523-547.

Jakes P. \& White A.J.R. 1972. Major and trace element abundances in volcanic rocks of orogenic areas. Geol. Soc. Amer. Bull, 83:29-40.

Jensen L.S. 1976. A new cation plot for classifying subalkalic volcanic rocks. Ont. Div. Mines, Misc. Pap., 66 p.

Lamarão C.N., Dall`Agnol R., Lafon J.M., Lima E.F. 2002. Geology, geochemistry, and $\mathrm{Pb}-\mathrm{Pb}$ zircon geochronology of the Paleoproterozoic magmatism of the Vila Riozinho, Tapajós Gold Province, Amazonian craton, Brazil. Prec. Res., 119:189-223.

Le Maitre R.W. 2002. A classification of igneous rocks and glossary of terms. 2nd, Edition, London, 193 pp.

Macambira E.M.B. \& Vale A.G. 1997. Projeto especial mapas de recursos minerais, de solo e de vegetação para a área do Projeto Grande Carajás - sub-programa mapas metalogenéticos e de previsão de recursos minerais. Folha São Félix do Xingu Regular Folha SB-22- 
$Y$-B. CPRM, SUREG, Belém.

Maniar P.D. \& Piccoli P.M. 1989. Tectonic Discrimination of granitoids. Geol. Soc. Amer. Bull., 101:635-643.

Miller C.F. \& Mittlefehldt D.W. 1982. Depletion of light rare-earth elements in felsic magmas. Geology, 10:129-133.

Miyashiro A. 1974. Volcanic rock series in Island Arcs and active continental margins. Am. J. Sci., 274:321-355.

Morrison G.W. 1980. Characteristics and tectonic setting of the shoshonite rock association. Lithos, 13:97-108.

Nardi L.V.S. \& Lima E.F. de. 1985. A associação shoshonítica de Lavras do Sul, RS. Rev. Bras. Geoc., 15:139-146.

Paiva Júnior A.L. 2004. Petrografia e geocronologia Pb-Pb do Granito Santa Rosa, região de São Félix do Xingu, Província Mineral de Carajás. In: UFPA, Seminário de Iniciação Científica da UFPa, 15, Belém, Atas, v. 1., p. 73.

Pearce J.A. 1996. Source and settings of granitic rocks. Episodes, 19:120-125.

Pearce J.A., Cann J.R. 1973. Tectonic setting of basic volcanic rocks determined using trace elements analyses. Earth Planet. Sci. Lett., 19:290-300.

Pearce J.A., Harris N.B.W., Tindle A.G. 1984. Trace element discrimination diagrams for the tectonic interpretation of granitic rocks. Journal of Petrology, 25:956-983.

Peccerillo A. \& Taylor S.R. 1976. Geochemistry of Eoceno Calc-Alkaline Volcanic Rocks from the Kastamonu Area, Northern Turkey. Contrib. Mineral Petrol., 58:63-81.

Pessoa M.R., Andrade A.F. de, Nascimento J.O. do, Santos J.O.S., Oliveira J.R. de, Lopes R. da C., Prazeres W.V. 1977. Projeto Jamanxim. Relatório Final. Manaus, CPRM/DNPM, V8.

Rollinson H. 1993. Using geochemical data: evaluation, presentation, interpretation. Zimbabwe, $344 \mathrm{p}$.

Sun S.S. \& Mcdonough W.F. 1989. Chemical and isotopic systematics of oceanic basalts: implications for mantle composition and processes. In: A.D. Saunders \& M.J. Norry (Eds), Magmatism in the Ocean Basins. Geol. Soc. London, v. 42, pp.: 313-345.
Tassinari C.C.G. \& Macambira M.J.B. 1999. Geochronological Provinces of the Amazonian Craton. Episodes, 22:174-182.

Teixeira, N.P. 1999. Contribuição ao estudo das rochas granitóides e mineralizações associadas da Suíte Intrusiva Velho Guilherme, Província Estanifera do Sul do Pará. Tese de Doutorado, Instituto de Geociências, Universidade de São Paulo, São Paulo, 508p.

Teixeira N.P., Fernandes C.M.D., Moura C.A.V., Pinho S.C.C., Bettencourt J.S. 2002a. Geologia, Geoquímica, Geocronologia e isótopos de Sm-Nd de rochas vulcânicas paleoproterozóicas do Grupo Uatumã ocorrentes na região de São Félix do Xingu, Província Mineral de Carajás, Cráton Amazônico, Brasil. In: SBG, Simp. sobre Vulc. e Amb. Assoc., 2., Belém, Boletim de Resumos e Roteiro da Excursão, p.28.

Teixeira N.P., Bettencourt J.S., Moura C.A.V., Dall'Agnol R., Macambira E.M.B. 2002b. Archean crustal sources for paleoproterozoic tingranites in the Carajás Province, SSE Pará, Brazil: $\mathrm{Pb}-\mathrm{Pb}$ geochronology and Nd isotope geochemistry. Prec. Res., 119:2257-2275.

Treuil M. \& Joron J. M. 1975. Utilisation des éléments hygromagmatophiles pour la simpli.cation de la modèlisation quantitative des processus magmatiques. Exemples del l'Afar et de la dorsade médioatlantique, Soc. It. Mineral. Petrol. 31:125-174.

Whalen J.B., Currie K.L., Chappell B.W. 1987. A-Type granite: geochemical characteristics, discrimination and petrogenesis. Contr. Mineral. Petrol., 95:407-419.

Wilson M. 1989. Igneous Petrogenesis: A global tectonic approach. Chapman \& Hall, London, $466 \mathrm{p}$.

Wood D.A., Joron J.M., Treuil M. 1979. A Re-appraisal of the use of trace elements to classify and discriminate between magma series erupted in different tectonic settings. Earth Planet. Sci. Lett., 45:326336. 